\title{
BEIJING '95
}

NGO FORUM ON WOMEN

...A THIN, THIN SLICE

Teresa Konechne 


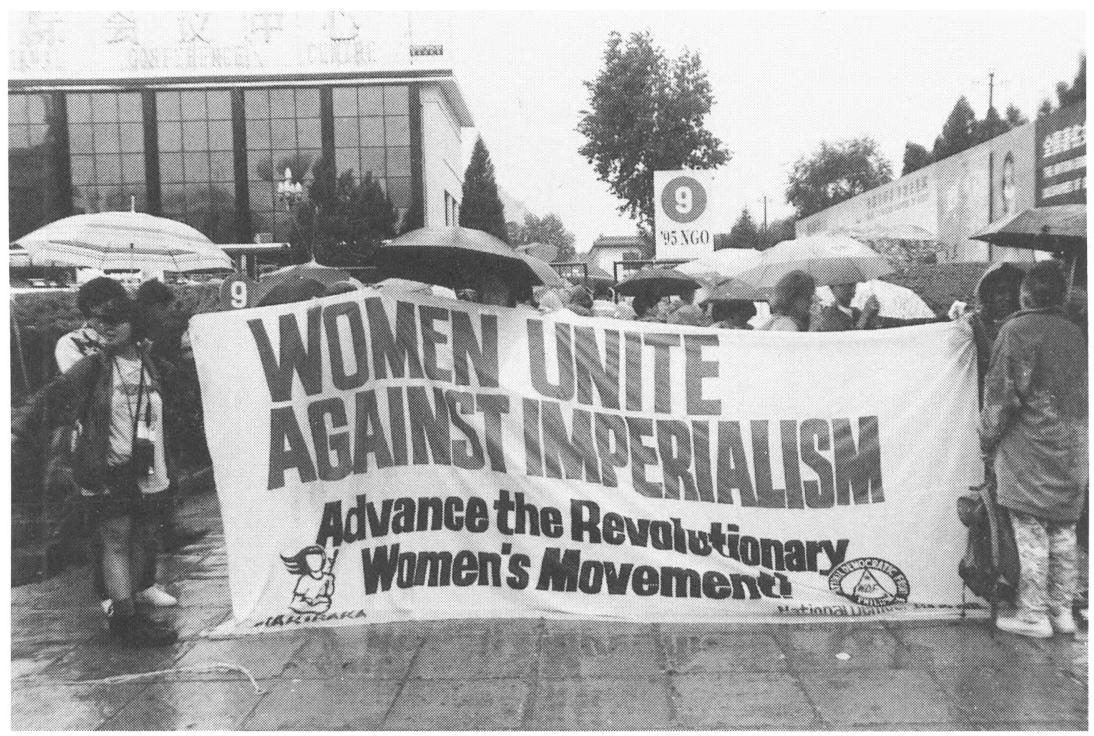

...outside Hillary's speech

locked gates/high security/rain

National Democratic Front 


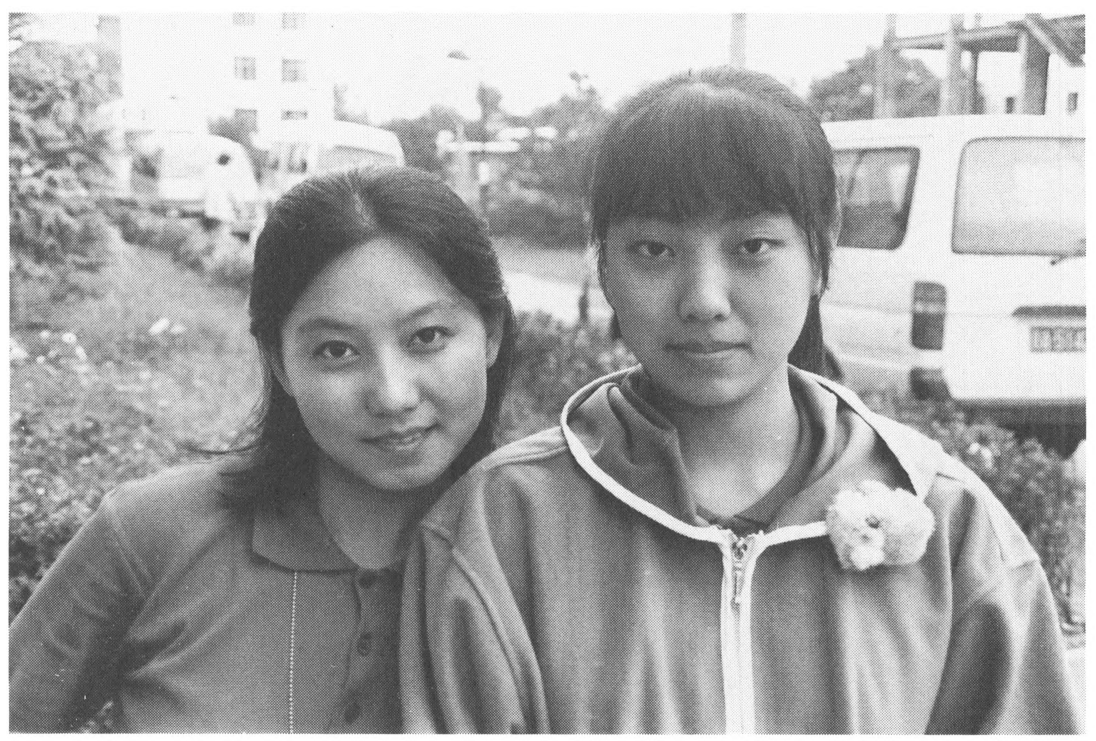

Carrie and Gui

Xerox shop workers

wages: $65 \not$ a day

copies: $15 \phi$ each 


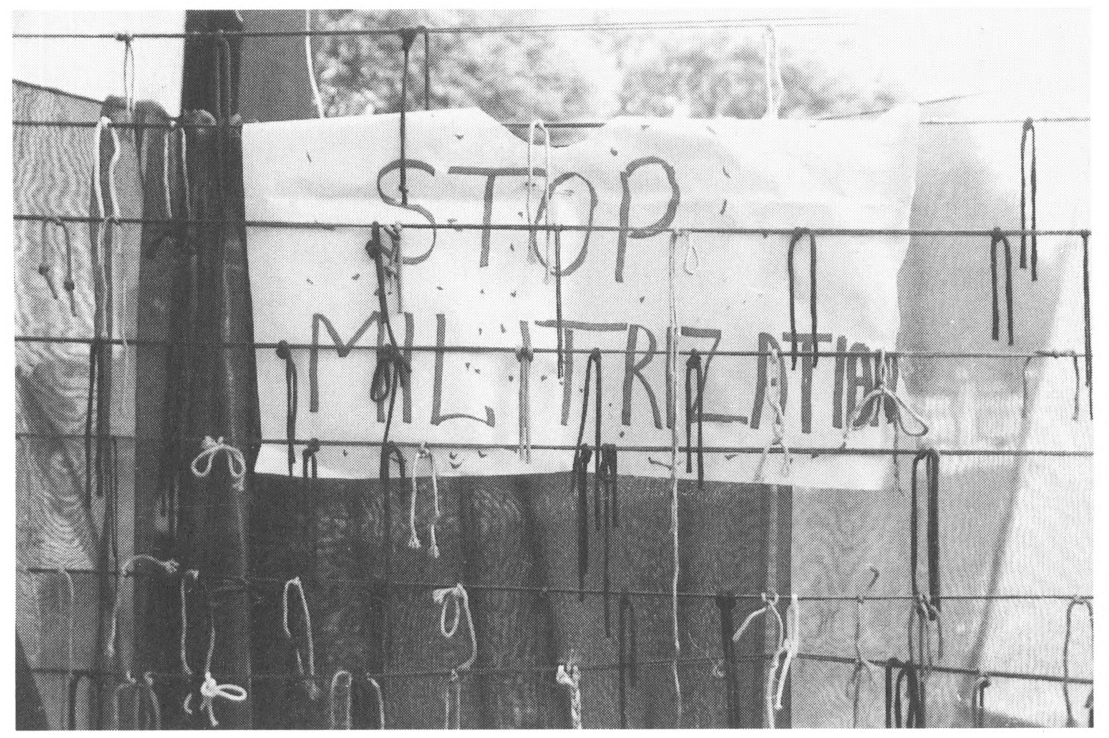

....tie a ribbon

installation about fundamentalism

peace tent 


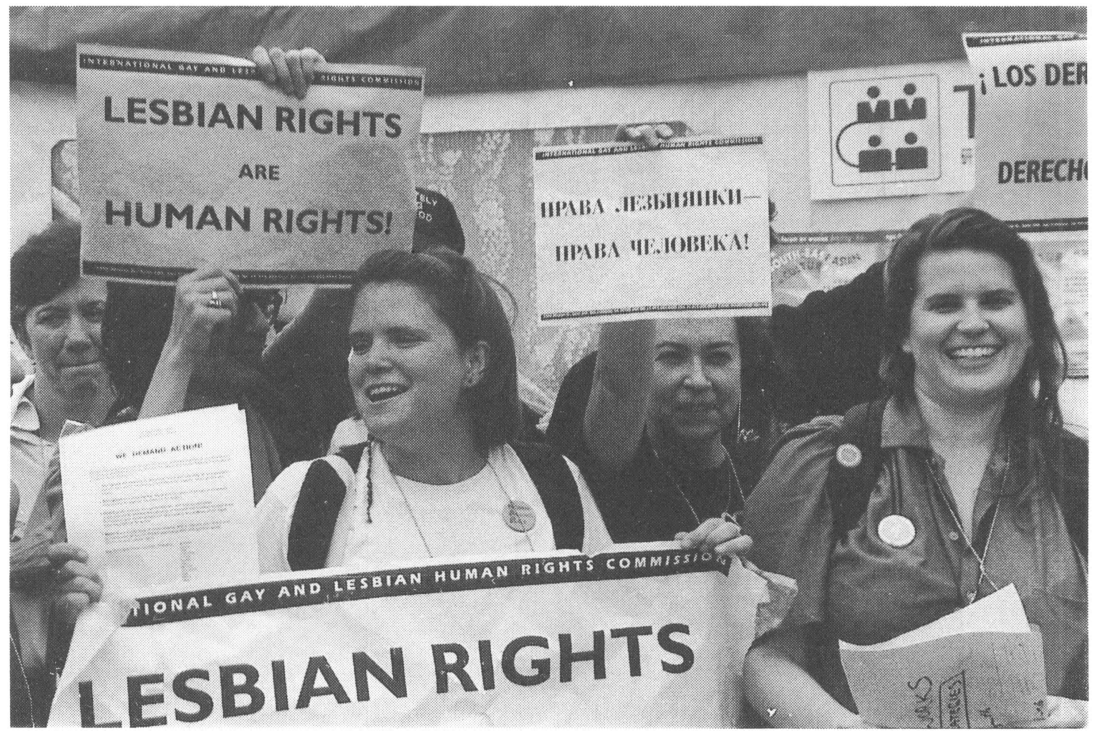

WE DEMAND ACTION

first lesbian march in the history

of the conference 


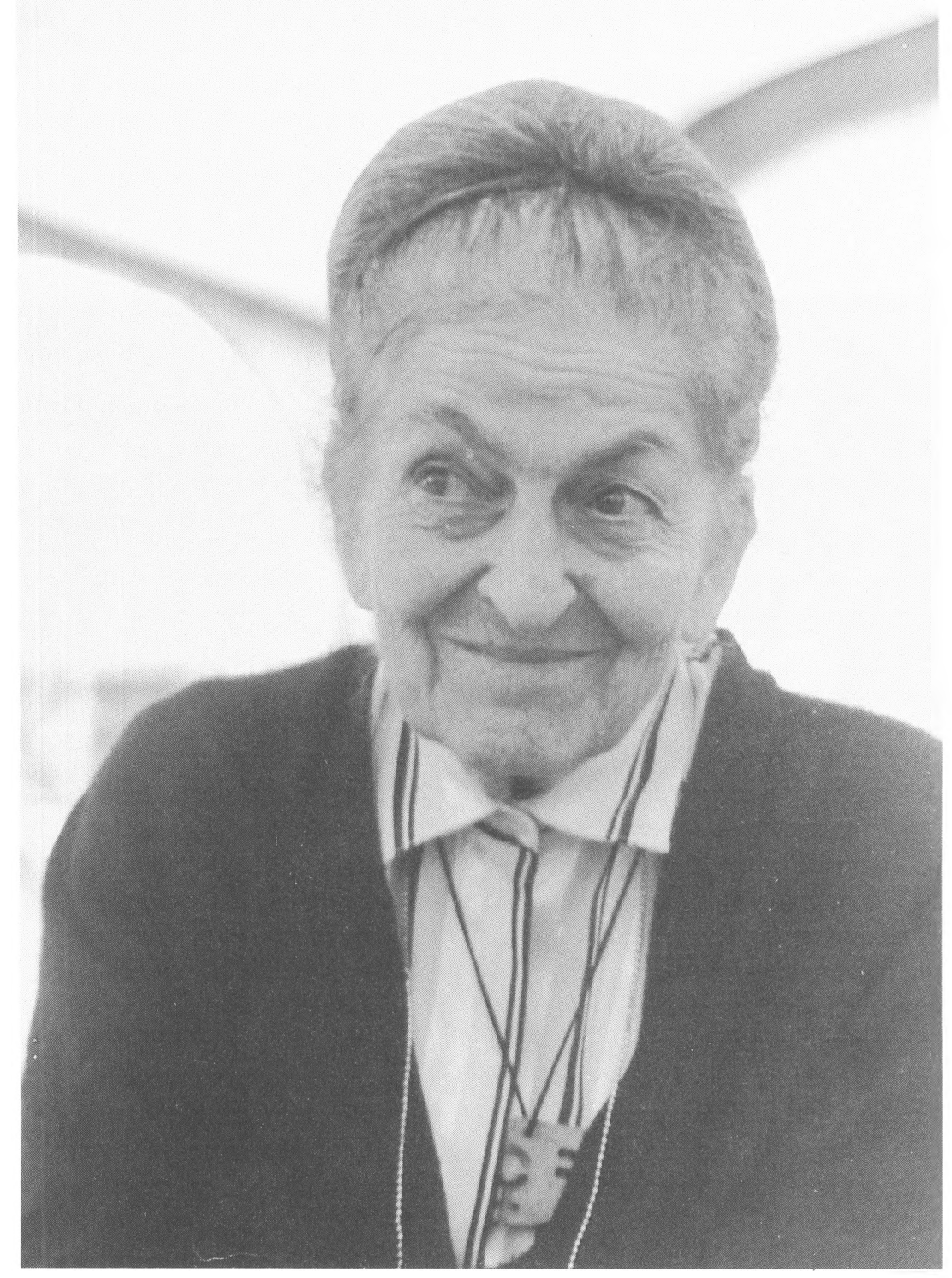

Anissa Majjar

Lebanon

82 years old

peace tent 


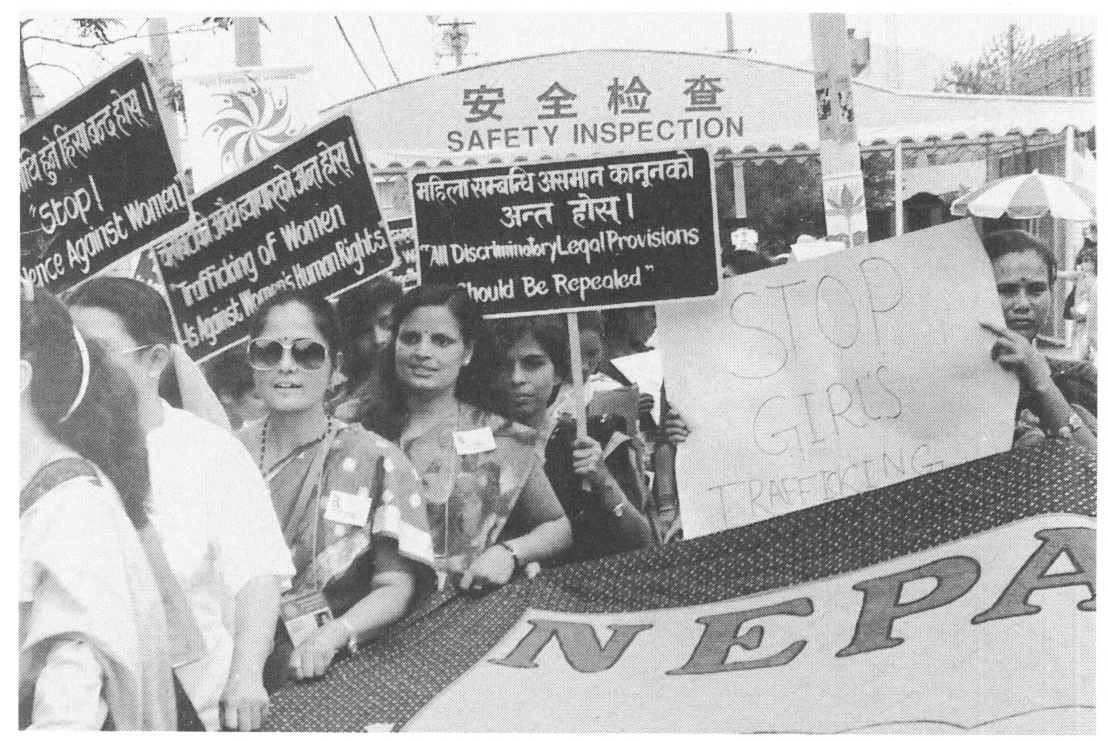

...women of the world ...unite ....unite sex trafficking protest

women of Nepal 


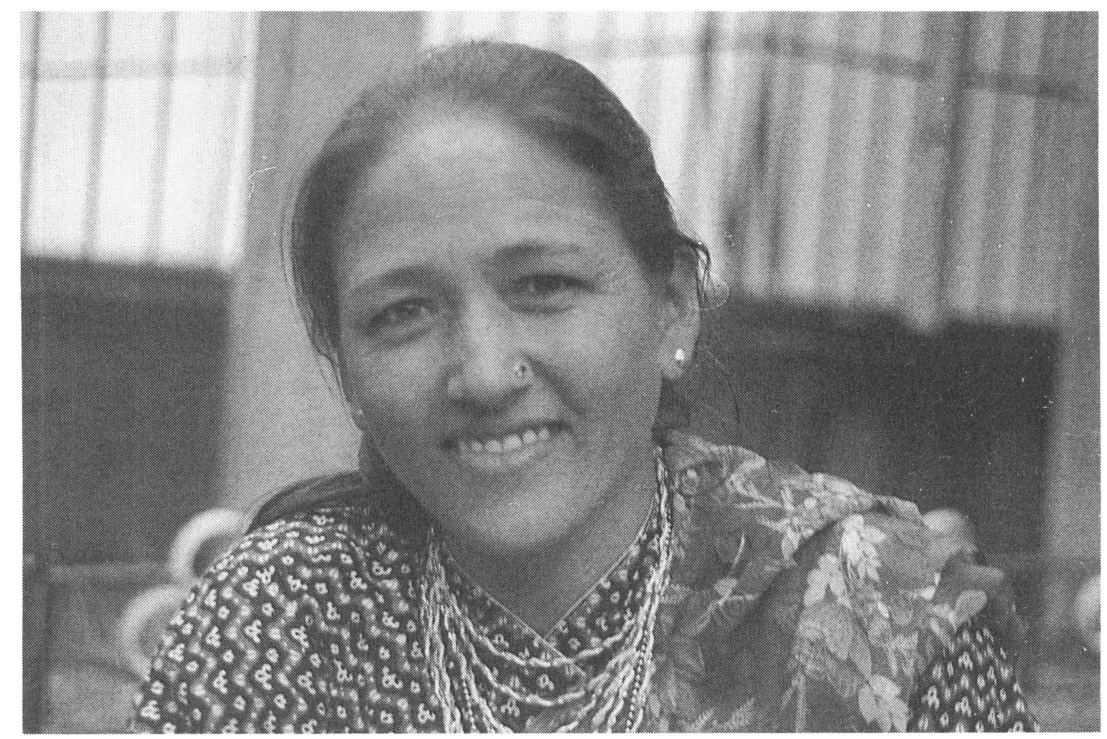

Mrs. Maina Bhandari, B.C.

selling her sisters' goods

"Laments of Nepalese Women"

(Revolutionary Song/Poem Collection)

from women who could not

attend the conference 


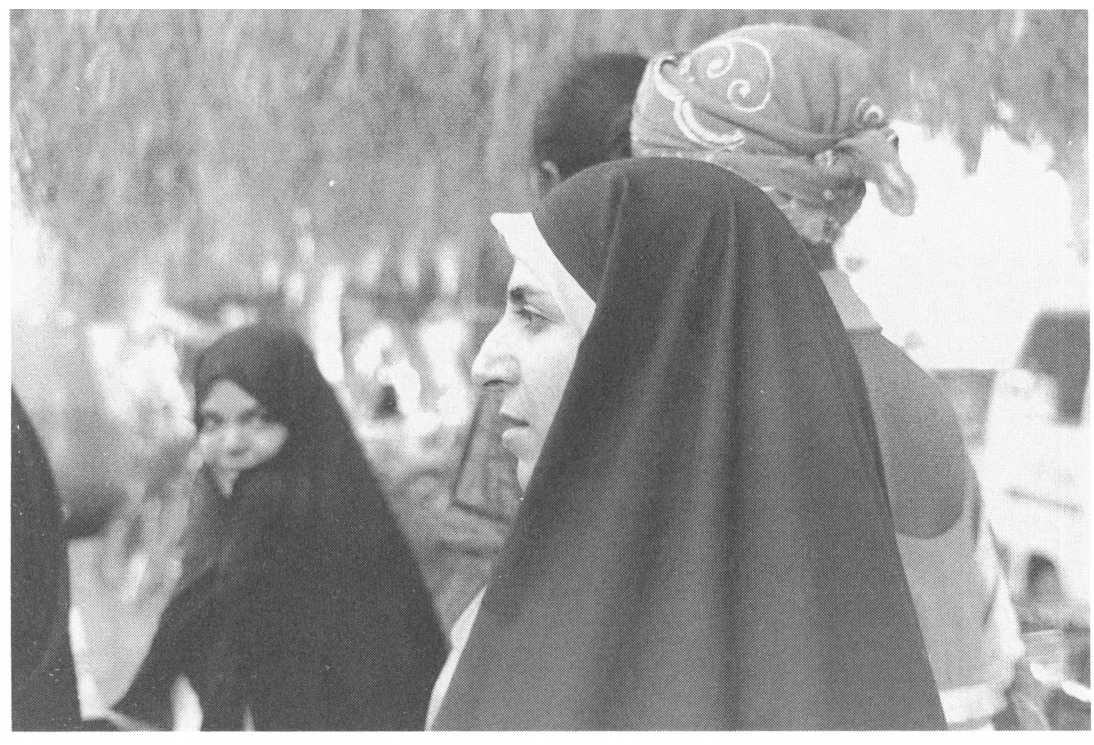

fundamentalists from Iran

sent by the government accompanied by

their husbands 